\title{
Poisoning causing the decline in South-East Asia's largest vulture population
}

\author{
ROBIN LOVERIDGE, GERARD EDWARD RYAN, PHEARUN SUM, \\ OLIVER GRAY-READ, SIMON P. MAHOOD, ALISTAIR MOULD, \\ STEFAN HARRISON, RACHEL CROUTHERS, SOK KO, TOM CLEMENTS, \\ JONATHAN C. EAMES and MATHIEU PRUVOT
}

\section{Summary}

Cambodia supports populations of three Critically Endangered vulture species that are believed to have become isolated from the rest of the species' global range. Until recently Cambodia's vulture populations had remained stable. However a recent spike in the number of reports of the use of poisons in hunting practices suggests the need to re-evaluate the conservation situation in Cambodia. Population trend analysis showed that since 2010 populations of the White-rumped Vulture Gyps bengalensis and Red-headed Vulture Sarcogyps calvus have declined, while the Slender-billed Vulture Gyps tenuirostris may also have started to decline since 2013. These trends are supported by evidence of reduced nesting success. A survey of veterinary drug availability revealed that diclofenac, the non-steroid anti-inflammatory drug responsible for vulture declines in South Asia was not available for sale in any of the 74 pharmacies surveyed. However, a poisoned Slender-billed Vulture tested positive for carbofuran in toxicology tests. This provides the first evidence of a vulture mortality resulting from carbofuran in Cambodia. The findings suggest the urgent need to tackle use of carbamate pesticides in hunting. Proposed conservation actions are: a) prevention of poisoning through national bans on harmful carbamate pesticides and diclofenac and education campaigns to reduce demand and use; b) training of personnel in priority protected areas in detection and response to poisoning incidents; c) maintenance of a safe and reliable food source through vulture restaurants to ensure short-term survival, and d) protection and restoration of large areas of deciduous dipterocarp forests to enable long-term species recovery.

\section{Introduction}

Vultures provide important ecosystem services (Moleon et al. 2014). They dispose of carrion 'providing a free and highly effective sanitation service' (Ogada et al. 2012a). They speed up carcass decomposition time and reduce the number of mammalian carcass visitors, which results in reduced contacts among mammalian scavengers at carcasses and suggests that vultures play a role in reducing levels of disease transmission (Ogada et al. 2012b). This is particularly important in countries with large populations of feral dogs, the main reservoir of diseases such as rabies (Sudarshan et al. 2007).

The primary threats facing global vulture populations are poisoning due to food sources containing lethal quantities of chemicals, including non-steroidal anti-inflammatory drugs (NSAIDs) and pesticides, and direct persecution (Gilbert et al. 2006, Margadila et al. 2008, Ogada et al. 2015, Margalida and Oliva-Vidal 2017). The catastrophic vulture population declines in South Asia, which began in the 1990s have received a great deal of international attention (Gilbert et al. 2006, Pain et al. 2008, Das et al. 2011, Margalida et al. 2014). The principal cause of these declines has been identified as secondary poisoning resulting from the NSAIDs that are used to treat cattle but 
are toxic to vultures (Green et al. 2004, 2006, Oaks et al. 2004). Similar declines and local extirpations of the White-rumped Vulture Gyps bengalensis, Slender-billed Vulture Gyps tenuirostris and Red-headed Vulture Sarcogyps calvus have been recorded across much of their native ranges in Laos, Vietnam and Thailand driven by secondary poisoning (BirdLife International 2017a, 2017b, $2017 \mathrm{c}$ ). These declines have led to the isolation of small but stable populations of these same species in Cambodia (Clements et al. 2013).

A consortium of NGO and government partners has supported conservation of Cambodian vultures since 2004. Previous research covering the period of 2004-2011 considered threats to Cambodian vultures and monitored nesting success, ranging behaviour and population trends (Clements et al. 2013). The results of that study indicated population sizes for the three resident vulture species to be in the range of 50-200+ individuals for each species, ranging across an area of approximately $75,000 \mathrm{~km}^{2}$, including adjacent areas in Laos and Vietnam. The principal detected causes of vulture mortality were poisoning in $73 \%$ of cases (Clements et al. 2013). However the chemicals responsible for these poisoning events were not identified.

In 2016 there was a spike in the number of wildlife poisoning events reported (WCS 2016). This suggests a renewed need to understand poisoning behaviour and evaluate possible impacts on the vulture populations in Cambodia. Our aims in this paper are to: 1 ) assess the population size and trend of the Cambodian vulture populations; 2) analyse the nature of the poisoning threat facing these populations, and 3) propose priority conservation actions.

\section{Methods}

The study was located at nine research sites across vulture range in Cambodia: Chhaep Wildlife Sanctuary (CWS, formerly Preah Vihear Protected Forest, since January 2003), Prey Siem Pang Kang Lech Wildlife Sanctuary (PSPKLWS, formerly Western Siem Pang Forest, since December 2004), Phnom Prich Wildlife Sanctuary (PPWS, since July 2005), Lomphat Wildlife Sanctuary (LWS, since October 2005), Srepok Willdife Sanctuary (SWS, formerly Mondulkiri Protected Forest, since October 2005), Kulen Promtep Wildlife Sanctuary (KPWS, since April 2007), Virachey National Park (VNP) and two areas not currently under formal protection the Sesan River (since June 2007), Mekong Flooded Forest (MFF) (Figure I). At each research site a supplemental feeding station (vulture restaurant) was established to provide cow and sometimes buffalo carcasses to monitor vulture population trends. The surrounding area was surveyed for threats, nesting sites, and vultures by project staff.

Five of the nine vulture restaurants implemented regular feeding events throughout the duration of this project and are considered 'long-term sites', while four of the nine vulture restaurants were used intermittently (Figure 1). Population monitoring data are presented here between 2004 and 2016. We focus on the three species of vulture regularly recorded and known to breed in Cambodia: the Red-headed Vulture, the Slender-billed Vulture, and White-rumped Vulture. Two other species are occasionally recorded as vagrants in Cambodia, namely Himalayan Griffon Gyps himalayensis and Cinereous Vulture Aegypius monachus; these species are not discussed further in this study.

\section{Analysis of vulture population size and trends}

We use two methods to assess the size and trend of Cambodian vulture populations: counts from regular feeding events held at vulture restaurants, which provide regular fine-grained information about vulture numbers over the year, and synchronised 'census' counts conducted simultaneously at all sites twice annually, which provide minimum population sizes.

\section{Counts from regular feeding events at long-term sites}

At the five long-term vulture restaurant sites (CWS, PSPKLWS, Sesan, LWS, and SWS) regular feeding events were conducted with at least one cow or buffalo carcass provided per month. 


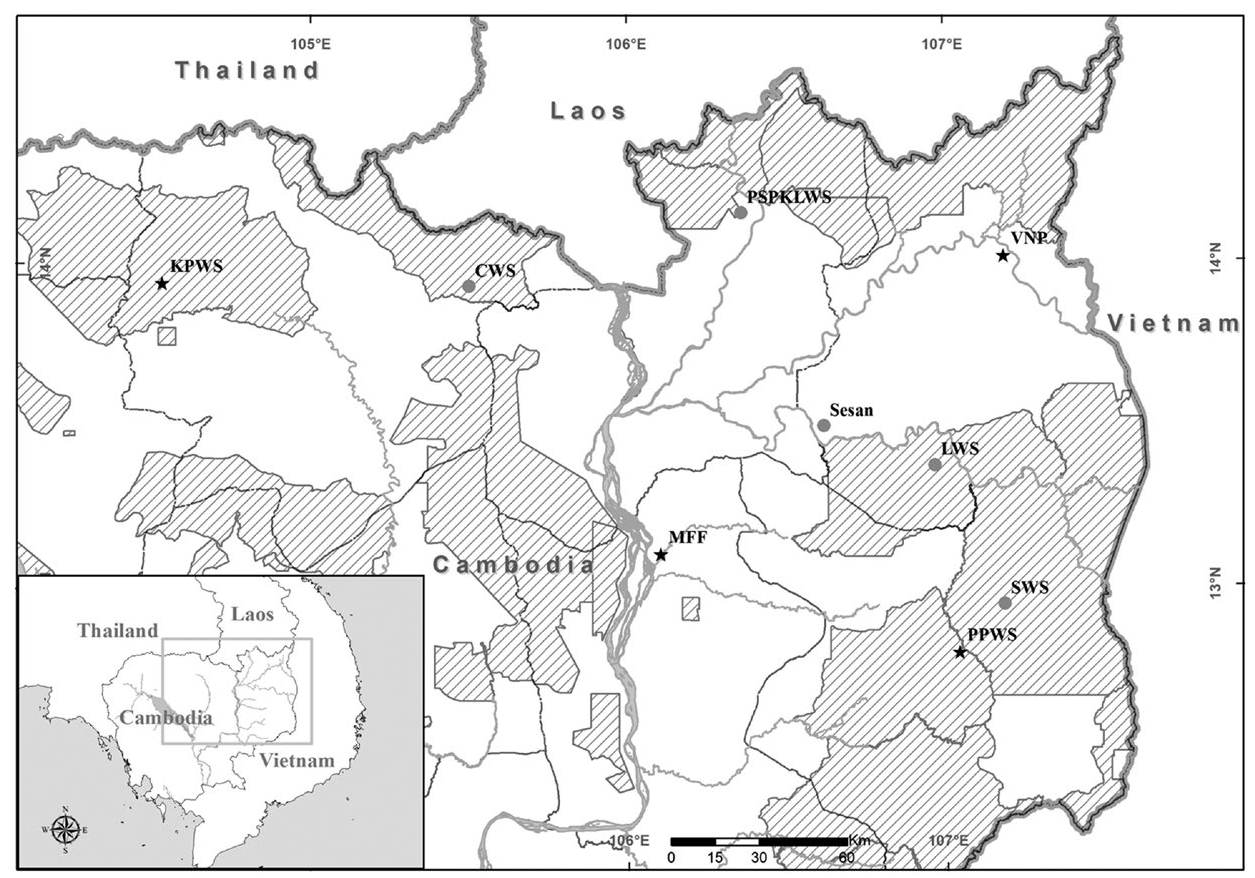

Figure 1. Map of vulture restaurant sites in Cambodia in 2016. Long-term restaurant sites are grey circles; intermittent restaurant sites are stars; international border is the solid grey line; priority protected areas are cross-hatched.

Initially restaurants were regularly alternated between PPWS and SWS, the two sites being in close proximity (Figure I), however since 2012 restaurants were only conducted at SWS. For the purpose of data analysis, here we combine restaurants conducted at SWS and PPWS, and treat them as a single site. Feeding was also conducted occasionally at other sites (VNP, MFF, and KPWS; Figure 1). At each feeding event, the total number of vultures, and the age, and sexes (in the case of Red-headed Vulture) of each species present were recorded. The number of feeding events conducted from February 2003 to June 2015 is reported in Table $S_{1}$ in the online supplementary material.

\section{Simultaneous 'census' counts}

In addition to regular feeding, country-wide population 'censuses' were conducted by feeding at all restaurant sites simultaneously. The aim of this method was to avoid duplicate counts and obtain minimum population estimates. Simultaneous census counts were conducted twice in June each year, with 10-14 days between each occasion, in 2004, and from 2006 to 2016.

\section{Data analysis}

For each species we fit two sets of generalised linear models: one to the regular feeding counts, and one to the simultaneous census counts. We analyse data from feeding at regular restaurants conducted between 23 February 2003 and 21 June 2016 only at long-term restaurant sites, and simultaneous censuses from 2004 to 2016 (excluding 2005, see above) at all sites. We fit fully nested sets of data to the number of vultures counted, and candidate model sets are listed in Table 1 . 
Table 1 . List of models fit to counts from regular feeding events, and simultaneous censuses. Each line represents a model where count was estimated as a function of the parameters listed.

\begin{tabular}{ll}
\hline Candidate models & \\
\hline Regular feeding counts & Simultaneous census counts \\
\hline date & constant \\
date & \\
dite & year \\
season & year \\
date $\times$ site & occasion \\
date $\times$ site & year + occasion \\
site $\times$ season & year + occasion \\
date $\times$ season & \\
date $\times$ season & \\
date $\times$ site $\times$ season & \\
date ${ }^{2} \times$ site $\times$ season & \\
\hline
\end{tabular}

For the regular restaurant data we modelled count at each site as a function of either a linear or quadratic effect of date, and fixed effects of site and season, and interactions among them. Season was a two-level factor of the six months with either the highest or lowest average rainfall in our study area, with "wet" from May to October, and "dry" from November to April (Heng 2015). For the census data we modelled the total count at all sites as a function of either a linear or quadratic effect of year, and an additive fixed effect of sampling occasions, i.e. the first or second of the two census occasions per year.

We expected strong effects of site on the number counted during regular feeding, so include this term in the regular feeding model set. Census occasion may be important if birds that were present at the first census occasion may not disperse widely after feeding and are more likely to be present at the second occasion. We did not have sufficient data to fit more complex (interactive) terms for this model. We also expected that in the period for which we had data, that populations were likely to increase, decrease, or one and then the other, and that most patterns would be best represented by simple linear and quadratic terms. Models were fitted with quasi-Poisson errors using a log-link function in R 3.2.4 (R Core Team 2016). The best models were selected by the lowest quasi-AICc score, and we demonstrate the level of support for the top models by reporting QAICc weight. To calculate QAICc scores and weights we also re-ran all models with standard Poisson errors, and corrected AICc scores using the dispersion from the most complex model in each set (date ${ }^{2} \times$ site $\times$ season, and date ${ }^{2}+$ occasion) using the R-package "bblme" (Bolker 2016). For the top model for the restaurant data we also conduct analysis of variance to test the significance of the predictor variables following Clements et al. (2013).

\section{Nest site monitoring}

Vulture nesting sites were identified by local rangers, with additional information provided by villagers beginning during October (the late wet season). All nesting locations discussed in Clements et al. (2013) were mapped and checked between 2011 and 2016 and we report here only new data collected unreported from Clements et al. (2013). Where nests were located, local people were sometimes employed as protectors at selected locations (and not across all sites), receiving a payment contingent on ensuring nests were not disturbed or destroyed by people, and the young fledged successfully. Data were recorded on vulture species, location and the characteristics of nesting sites and verified by project staff. Repeat visits by project staff were undertaken throughout the breeding season, extending into May (early wet season), in order to determine the number of chicks that successfully fledged. Percentage nesting success from first identification to fledging was calculated for all sites. Additionally, the probability of survival from the first emergence of 
the chick to fledging was calculated for PSPKLWS, the site where most nests were observed and detailed observation data allowed identification of different stages of the nesting cycle. We do not attempt a comparison with the earlier phase of the vulture conservation project (Clements et al. 2013) due to the more ad hoc nature of nest monitoring in this earlier phase making a comparison of survival probabilities less robust (Mayfield 1975).

\section{Pharmacy and animal husbandry survey on availability and use of veterinary drugs}

Two questionnaire surveys were undertaken to assess availability and attitudes towards use of veterinary drugs in PSPKLWS, SWS, CWS, PPWS, KPWS, Sesan and MFF. Firstly, availability of veterinary drugs was assessed by surveys of all shops where veterinary drugs were found on sale in target villages and in all pharmacies in the provincial capitals of the four provinces surveyed. The resulting drugs list was compared with a list of NSAIDs tested and found to be toxic to vultures by health industry and conservation experts. Secondly, attitudes towards use of veterinary drugs use were assessed by interviews conducted with livestock owners in target villages. Fourteen undergraduate students were recruited from the Environmental Department of Pannasastra University of Cambodia to conduct all questionnaire surveys. Students underwent a one-day training workshop and received logistical and technical support from Cambodia Vulture Conservation Project staff at each site.

\section{Monitoring and responding to poisoning events}

Animal carcass poisoning events were detected by a) field staff undertaking other protected area management activities in areas where vultures are known to be present and checking carcasses attended by vulture flocks for the presence/absence of dead vultures close to carcasses, and b) by following up on reports from local people about poisoning incidents. Direct observations of carcasses were made as quickly as possible after reports were received. Poisoned carcasses were destroyed by burning to prevent further vulture mortality and dead vulture carcasses were sent to the Wildlife Conservation Society (WCS) Wildlife Health programme for necropsy. On two occasions, involving one White-rumped Vulture and two Slender-billed Vultures, live birds were rehabilitated and released at their original capture location at PSPKLWS.

\section{Results}

\section{Vulture population size and trends}

\section{$\underline{\text { Simultaneous 'census' counts }}$}

The 2016 census indicates a minimum population of 109 White-rumped Vultures, 37 Slenderbilled Vultures and 26 Red-headed Vultures (Figure 2). The top models for all species was the year ${ }^{2}$ model, with weight of 0.62 for Red-headed Vulture, 0.4 for Slender-billed Vulture, and o.63 for White-rumped Vulture (Table S2). For Slender-billed Vulture and White-rumped Vulture the year ${ }^{2}+$ occasion model also received a high level of support (weights of 0.24 and 0.37 respectively, and both $\triangle$ QAICc of 1 ; Table S2).

In all cases counts were estimated to have initially risen from 2004, and then fallen in recent years. The trend was most striking in White-rumped Vulture with a distinct 'hump-shaped' curve: a steady increase was observed from 90 individuals in 2004, to a peak of 201 individuals in 2010, followed by a decline to 109 individuals in 2016. Slender-billed Vulture shows a less extreme version of this curve shape, increasing from 34 individuals in 2004 to a maximum of 68 in 2013, then declining to 37 individuals in the 2016 census (lower than the average of 49 across the study period). Red-headed Vulture counts have shown a downward trend in counts and minimum population estimates from 58 individuals in 2006 to 26 in 2016. 


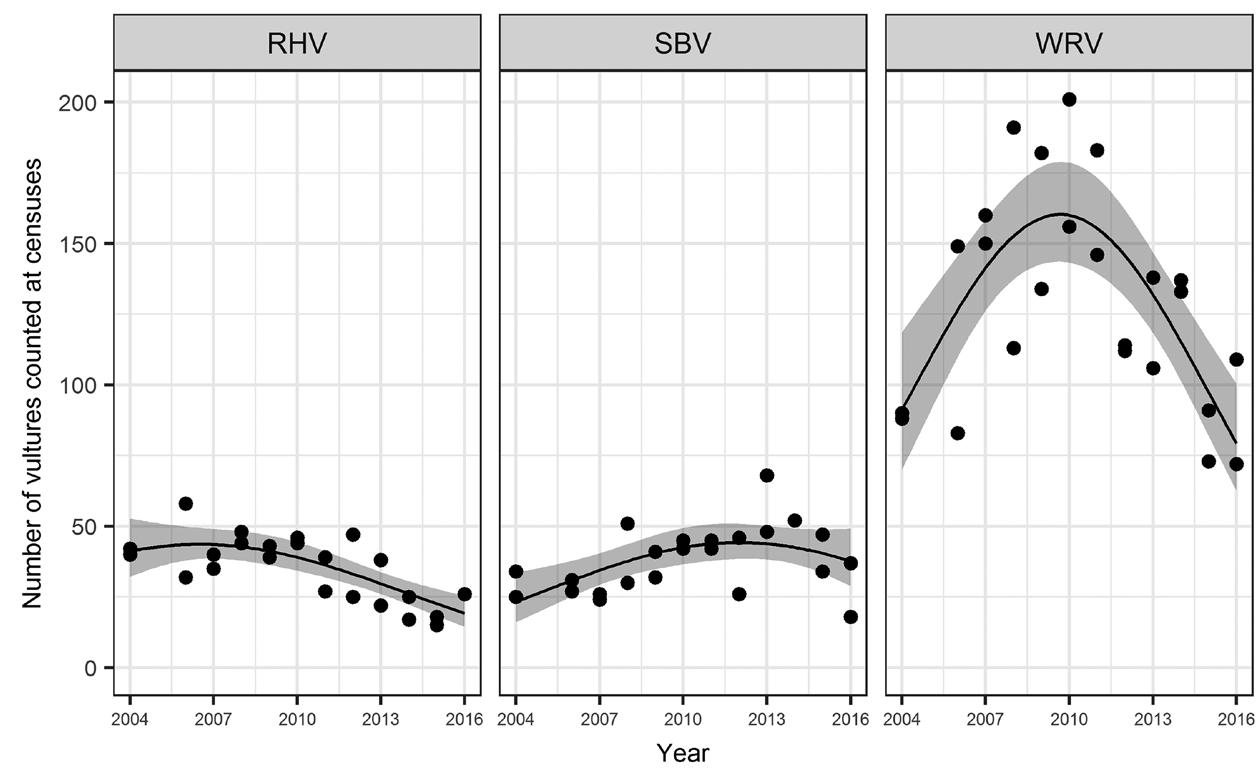

Figure 2. Counts of Red-headed Vultures (RHV), Slender-billed Vultures (SBV) and Whiterumped Vultures (WRV) recorded at annual census counts coordinated at all restaurant sites between June 2004 and 2016 (points), with estimated mean count from top models (line) and 95\% confidence interval of the mean (grey ribbon).

\section{Counts from regular counts at long-term sites}

At vulture restaurants, for all species, the counts of birds were best modelled date ${ }^{2} \times$ site $\times$ season. For all species this model was the best supported, by more than $13 \Delta \mathrm{qAICc}$, and estimated to have almost all weight among the candidate set (Table $\mathrm{S}_{2}$ ). As well as the very strong support for these models demonstrated by these model weights (Burnham et al. 2011), analysis of variance shows that both the effects of the quadratic function of time, the effect of site, and the interactions between them were highly significant for all species, while the effect of season was only significant for Red-headed and White-rumped Vulture, and the interaction terms for season with either date or site were only significant for Slender-billed Vulture, and the three-way interactions significant for Slender-billed Vulture and White-rumped Vulture (Table 2). The expected counts for each species, the $95 \%$ confidence interval, and the actual restaurant counts at each site are shown in Figure 3, averaged by season. The coefficient estimates in Table 3 show the magnitude and

Table 2. Analysis of variance for generalized linear models for numbers of Red-headed Vulture (RHV), Slender-billed Vulture (SBV) and White-rumped Vulture (WRV) recorded at restaurant sites. * denotes $P<0.05$, and ${ }^{* * *} P<0.0001$.

\begin{tabular}{lllll}
\hline Variable & Degrees of freedom & F (significance) & & \\
\cline { 3 - 5 } & & RHV & SBV & WRV \\
\hline Date $^{2}$ & 2 & $114^{* * *}$ & $11.5^{* * *}$ & $18.6^{* * *}$ \\
Site & 4 & $68.8^{* * *}$ & $310^{* * *}$ & $38^{* * *}$ \\
Season & 1 & $34.4^{* * *}$ & $6.4^{*}$ & 0.3 \\
Date $^{*}$ site & 8 & $8.8^{* * *}$ & $13.9^{* * *}$ & $29.0^{* * *}$ \\
Date $^{* *}$ season & 2 & 2.1 & $4.5^{*}$ & 0.1 \\
Site $^{*}$ season & 4 & 1.5 & $3.2^{*}$ & 2.2 \\
Date $^{2 *}$ site & 8 & 0.5 & $2.4^{*}$ & $2.2^{*}$ \\
\hline
\end{tabular}




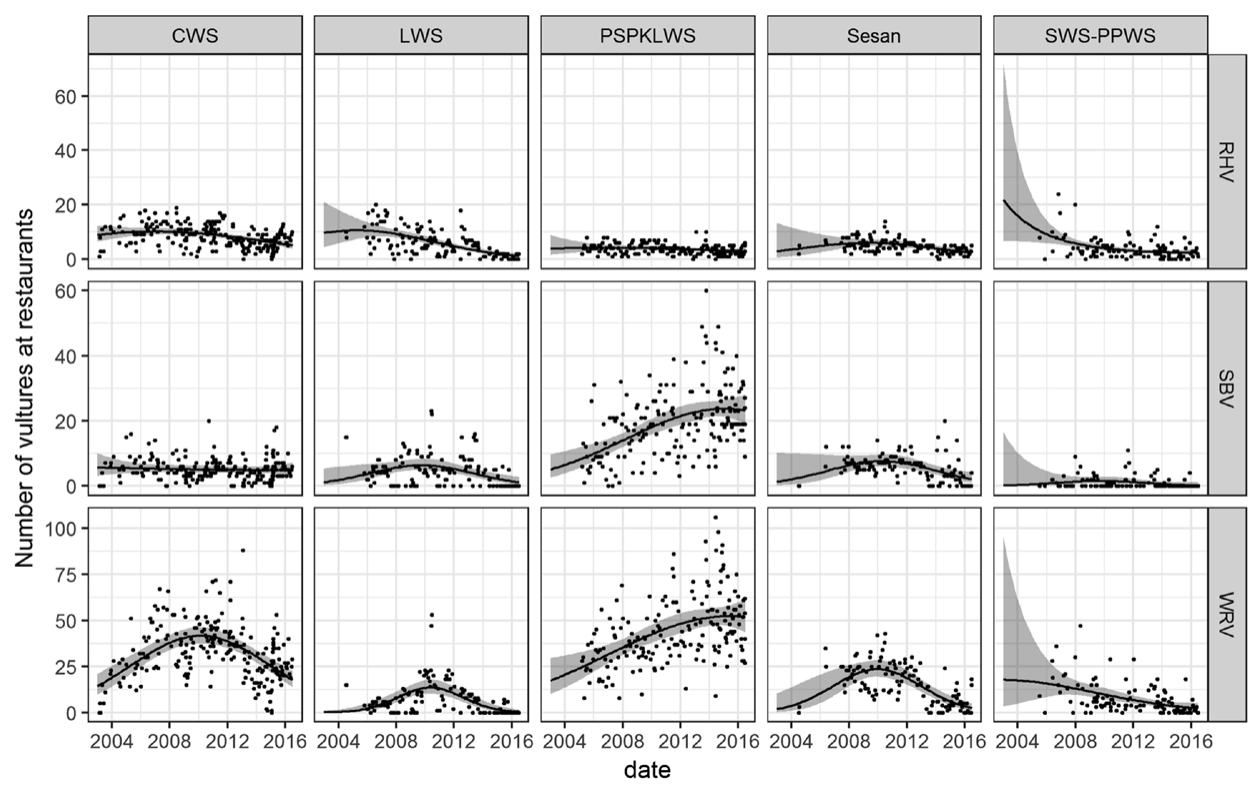

Figure 3. Numbers of White-rumped Vulture (WRV), Slender-billed Vulture (SBV) and Redheaded Vulture (RHV) recorded at the five main vulture restaurants from January 2003 to June 2016 (points).

statistical significance of each predictor variable in these models, with the effect of sites relative to CWS as the reference site.

For Slender-billed and White-rumped Vultures, PSPKLWS and CWS are clearly the most important sites with the largest numbers seen (Figure 3) and the positive coefficient estimates for the site effect of PSPKLWS, and negative coefficient estimates for other sites relative to CWS. Both sites are located in the north and west of the study area. Sites in the south and east, LWS, SWS-PPWS, and Sesan have fewer numbers of all species and the steepest declines; this is demonstrated by the negative coefficient estimates for the interaction terms for each site ${ }^{*}$ date and site $^{*}$ date $^{2}$ as compared to CWS for both Slender-billed Vulture and White-rumped Vulture (Table 3). Indeed $90 \%$ of White-rumped Vultures are now recorded in the northern-most sites of CWS and PSPKLWS. LWS is of particular concern for all species, showing the steepest declines overall. Estimates of the effect of season suggest that more White-rumped Vulture are counted in the dry season, and more Slender-billed Vulture in the wet, though neither term is significant.

The number of Red-headed Vultures attending restaurants is more uniformly distributed across the landscape with no site ever recording more than 25 individuals. All sites show a pattern of decline in recent years, though again the south-eastern sites appear to show steeper declines than the north-western sites (Figure 3, Table 3). Wet season counts are estimated to be statistically significantly greater for Red-headed Vulture (Table 3 ).

Taken together, the census and regular restaurant data create a picture of the general trend in Cambodia's vulture populations. Overall, the highest number of Slender-billed Vulture and Whiterumped Vulture were recorded at PSPKLWS around 2013-2014, numbers recorded at restaurants in subsequent years are typically fewer. Red-headed Vultures were most often encountered at SWS-PPWS, CWS, and LWS in 2007-2009. Combined with the census data showing initial increases followed by declines in total birds counted, this is evidence that each of these populations is likely to have declined. The predicted mean counts and $95 \%$ confidence intervals for the best fitting generalized linear model of vulture numbers are also shown, averaged by season (line and ribbon). 
Table 3. Coefficient estimates from generalized linear models of number of vultures recorded at restaurants, where CWS is used as the reference site, and "dry" is the reference season. Small $P$-values are highlighted such that ${ }^{*}$ denotes $P<0.05,{ }^{* *} P<0.01$, and ${ }^{* *} P<0.001$.

\begin{tabular}{|c|c|c|c|c|c|}
\hline Parameter & Estimate & Standard Error & t-value & p-value & \\
\hline \multicolumn{6}{|l|}{ Red-headed Vulture } \\
\hline Intercept & 1.9 & 0.0 & 42.2 & $<2 \mathrm{E}-16$ & $* * *$ \\
\hline Date & -6.7 & 1.3 & $-5 \cdot 3$ & $1.8 \mathrm{E}-\mathrm{O} 7$ & $* * *$ \\
\hline Date $^{2}$ & -2.1 & 1.0 & -2.1 & 0.038 & * \\
\hline Site-LWS & -0.5 & 0.1 & $-4 \cdot 7$ & $2.9 \mathrm{E}-06$ & $* * *$ \\
\hline Site-PSPKLWS & -0.7 & 0.1 & -8.4 & $2.3 \mathrm{E}-16$ & $* * *$ \\
\hline Site-Sesan & -0.5 & 0.1 & -4.2 & $3.2 \mathrm{E}-\mathrm{O} 5$ & $* * *$ \\
\hline Site-SWS-PPWS & -0.6 & 0.1 & -6.0 & $3.9 \mathrm{E}-09$ & $* * *$ \\
\hline Season-wet & 0.3 & 0.1 & 5.6 & $2.6 \mathrm{E}-\mathrm{o} 8$ & $* * *$ \\
\hline Date* site-LWS & $-13 \cdot 3$ & 3.1 & $-4 \cdot 3$ & 2.1E-O5 & $* * *$ \\
\hline Date* site-SWS-PPWS & -8.9 & 3.0 & -2.9 & 0.0035 & $* *$ \\
\hline Site-SWS-PPWS* season-wet & -0.3 & 0.1 & -2.0 & 0.048 & * \\
\hline \multicolumn{6}{|l|}{ Slender-billed Vulture } \\
\hline Intercept & 1.6 & 0.1 & 21.8 & $<2 \mathrm{E}-16$ & $* * *$ \\
\hline Site-LWS & -0.6 & 0.2 & $-3 \cdot 3$ & 0.00099 & $* * *$ \\
\hline Site-PSPKLWS & 1.3 & 0.1 & 14.7 & $<2 \mathrm{E}-16$ & $* * *$ \\
\hline Site-SWS-PPWS & -1.8 & 0.3 & $-5 \cdot 4$ & $7 \cdot 4 \mathrm{E}-08$ & $* * *$ \\
\hline Date $^{2 *}$ site-LWS & -16.5 & 5.8 & -2.9 & 0.0045 & $* *$ \\
\hline Date*site-PSPKLWS & 6.4 & 2.4 & 2.7 & 0.0070 & $* *$ \\
\hline Date $^{2 *}$ site-Sesan & $-13 \cdot 7$ & 6.0 & -2.3 & 0.0219 & * \\
\hline Date* site-SWS-PPWS & -22.7 & $9 \cdot 4$ & -2.4 & 0.016 & * \\
\hline Site-LWS*season-wet & 0.7 & 0.2 & 2.9 & 0.0041 & $* *$ \\
\hline Date $^{2 *}$ site-PSPKLWS* season-wet & $-7 \cdot 7$ & $3 \cdot 3$ & -2.4 & 0.018 & * \\
\hline \multicolumn{6}{|l|}{ White-rumped Vulture } \\
\hline Intercept & $3 \cdot 5$ & 0.0 & 91.3 & $<2 \mathrm{E}-16$ & $* * *$ \\
\hline Date & -3.0 & 1.1 & -2.7 & 0.0082 & $* *$ \\
\hline Date $^{2}$ & -6.5 & 1.0 & -6.5 & $1.8 \mathrm{E}-10$ & $* * *$ \\
\hline Site-LWS & -2.5 & 0.3 & -8.8 & $<2 \mathrm{E}-16$ & $* * *$ \\
\hline Site-PSPKLWS & 0.3 & 0.1 & $4 \cdot 9$ & $1.3 \mathrm{E}-06$ & $* * *$ \\
\hline Site-Sesan & -1.2 & 0.2 & $-7 \cdot 5$ & $1.7 \mathrm{E}-13$ & $* * *$ \\
\hline Site-SWS-PPWS & -1.6 & 0.1 & -10.7 & $<2 \mathrm{E}-16$ & $* * *$ \\
\hline Date $^{2 *}$ site-LWS & -32.6 & 8.6 & -3.8 & 0.00018 & $* * *$ \\
\hline Date* site-PSPKLWS & 8.0 & 1.6 & 5.0 & $7 \cdot 4 \mathrm{E}-07$ & $* * *$ \\
\hline Date $^{2 *}$ site-PSPKLWS & 6.0 & 1.6 & $3 \cdot 7$ & 0.00023 & $* * *$ \\
\hline Date $^{2 *}$ site-Sesan & -16.0 & $5 \cdot 5$ & -2.9 & 0.0035 & $* *$ \\
\hline Date* site-SWS-PPWS & $-15 \cdot 9$ & $4 \cdot 3$ & $-3 \cdot 7$ & 0.00024 & $* * *$ \\
\hline Site-LWS* season-wet & 0.9 & 0.3 & 2.9 & 0.0036 & $* *$ \\
\hline Date $^{2 *}$ site-LWS ${ }^{*}$ season-wet & 19.6 & 9.6 & 2.0 & 0.042 & * \\
\hline Date $^{2 *}$ site-Sesan ${ }^{*}$ season-wet & 12.9 & 6.2 & 2.1 & 0.036 & * \\
\hline
\end{tabular}

\section{Nest site monitoring}

Nests of all three species were located, primarily at PSPKLWS and CWS. Total fledging success across all sites declined during the reporting period, although fledging success appears to have remained high at PSPKLWS (Table 4). The number of nests recorded at Sesan declined between 2011 and 2016 and no nests were found in 2016. No nests were found at SWS and PPWS where vulture nests were formerly frequently found. Nests of White-rumped Vulture and Red-headed Vulture were found in the MFF for the first time in 2011-2012. Slenderbilled Vulture and White-rumped Vulture nested separately; although the only White-rumped Vulture nest recorded at PSPKLWS was found within $500 \mathrm{~m}$ of a nesting Slender-billed Vulture. 
Table 4. Vulture nests recorded during 2011-2016 across all sites, and the number of birds known to have fledged.

\begin{tabular}{|c|c|c|c|c|c|c|c|c|}
\hline \multirow[t]{2}{*}{ Year } & \multicolumn{2}{|c|}{$\begin{array}{l}\text { Red-headed } \\
\text { Vulture }\end{array}$} & \multicolumn{2}{|c|}{$\begin{array}{l}\text { White-rumped } \\
\text { Vulture }\end{array}$} & \multicolumn{2}{|c|}{$\begin{array}{l}\text { Slender-billed } \\
\text { Vulture }\end{array}$} & \multirow{2}{*}{$\begin{array}{l}\text { All sites and } \\
\text { all species } \\
\text { fledging } \\
\text { success (\%) }\end{array}$} & \multirow{2}{*}{$\begin{array}{l}\text { All species chick } \\
\text { to fledging daily } \\
\text { survival rate at } \\
\text { PSPKLWS }\end{array}$} \\
\hline & Nests & Fledged & Nests & Fledged & Nested & Fledged & & \\
\hline $2011-12$ & 3 & 1 & 7 & 7 & 3 & 3 & 85 & 0.99 \\
\hline $2012-13$ & 1 & 1 & 13 & 12 & II & 8 & 84 & $I$ \\
\hline $2013-14$ & 1 & 1 & 6 & 5 & 12 & 10 & 84 & 0.99 \\
\hline $2014-15$ & 3 & 3 & 6 & 5 & 18 & 11 & 70 & 0.99 \\
\hline $2015-16$ & 6 & 5 & 4 & 3 & 13 & 4 & 52 & 0.99 \\
\hline Total & 14 & 11 & 36 & 32 & 57 & 36 & & \\
\hline
\end{tabular}

Nesting trees were large and tall, often of the Dipterocarpaceae family. In all cases only one chick per nest was observed. Evidence of abandonment of a nesting area as a result of economic land concession development was found at Phnom Taprom in Sesan District, Stung Treng Province, where the forest was cleared and replaced with a rubber tree plantation in 2011.

\section{Household and pharmacy survey on the use of veterinary drugs (diclofenac and NSAIDs) in Cambodia}

A total of 74 interviews were conducted at pharmacies. Diclofenac was not available for sale in pharmacies in veterinary form. A total of 104 veterinary-use drug formulations and 48 humanuse formulations were recorded in the survey. No NSAIDs were identified from the list of veterinary-use formulations. Two NSAIDs which have been found to be toxic to vultures were recorded in human-use products (diclofenac and aceclofenac), however the actual formulations available were not suitable for use on cattle (pill form or injectable solution in small quantity). Interviews were conducted with 1,540 livestock-owning households from 58 villages. Treatment of injured or sick animals using veterinary or commercial bought drugs was only reported by $12 \%$ of respondents.

\section{Mortality events}

Fifteen vulture poisoning events were recorded between January 2005 and 2016. This resulted in the known deaths of nine Red-headed Vultures, 32 White-rumped Vultures and 1o Slenderbilled Vultures. Of these, four vulture poisoning events were reported between 2010 and 2016, resulting in the deaths of 26 vultures (Table 5). Poisons implicated in their deaths had been used for a variety of reasons including hunting, pest control and crime. Contextual information gathered about the motivations and causes for recent poisoning events are I) deliberate poisoning of feral and domestic dogs, 2) accidental cow poisoning and 3) secondary poisoning resulting from indiscriminate use of poisonous chemicals in hunting practices (Table 5). Intentional wildlife poisoning of a forest pool in PSPKLWS resulted in the death of a Slender-billed Vulture in 2015. Laboratory testing was negative for NSAID residues, but positive for the presence of carbofuran residues. This provides the first documented proof of carbofuran exposure leading to vulture mortality in Cambodia. The August 2015 vulture poisoning incident occurred during a series of wildlife poisoning events in the Preah Vihear Province linked to use of carbofuran to deliberately poison wildlife as an indiscriminate approach to hunting (WCS 2016). 
Table 5. Recorded incidences of vulture mortality from 2011 to 2016; for 2005-2010 see Clements et al. (2013).

\begin{tabular}{|c|c|c|c|c|c|c|c|}
\hline Date & Location & Cause & RHV & WRV & SBV & Total & Action taken \\
\hline 1-Nov-12 & PSPLWS & Poisoned cow & o & 3 & o & 3 & $\begin{array}{l}\text { Contaminated vulture meat } \\
\text { confiscated. Cow carcass } \\
\text { burned. }\end{array}$ \\
\hline 28-Feb-14 & SPWS & Poisoned cow & 2 & 11 & 3 & 16 & Necropsy performed \\
\hline $11-A p r-15$ & PSPKLWS & Poisoned dog & o & $\mathrm{o}$ & 6 & 6 & Carcasses burned \\
\hline \multirow[t]{2}{*}{ 23-Aug-15 } & PSPKLWS & $\begin{array}{l}\text { Poisoned forest } \\
\text { pool }\end{array}$ & $\mathrm{o}$ & $\mathrm{o}$ & 1 & 1 & $\begin{array}{l}\text { Sample sent for toxicology } \\
\text { testing }\end{array}$ \\
\hline & Total & & 2 & 14 & 10 & 26 & \\
\hline
\end{tabular}

\section{Discussion}

\section{Population size and trends of vultures in Cambodia}

The findings of this study suggest that the vulture populations of Cambodia are in decline and that this decline is due to secondary poisoning. Similar patterns of poisoning driven declines have been observed for other vulture populations, such as the decline and extinction of the Bearded Vulture Gypaetus barbatus across much of Europe due to direct persecution by people (Hiraldo et al. 1979, Margalida et al. 2008), secondary poisoning causing vulture population declines in Pakistan (Oaks et al. 2004) and the collapse of Africa's vulture populations due to pesticide poisoning (Ogada et al. 2012a, 2015).

Analysis of the census data and regular feeding events (Figures 2 and 3, Table 3 ) suggest a marked decline since the publication of Clements et al. (2013). This conclusion is supported by evidence of reduced range of sites used for nesting, reduced nesting success at those remaining sites (Table 4), and ongoing evidence of poisoning and mass mortality events (Table 5). Although the date of maximum number of individuals observed at various sites varies by sites and species, the general trend observed in both the simultaneous censuses and the regular feeding events is that the number of individuals observed increased early in the study, only to decrease in the most recent years (2014-2016), for all three species (Figures 2 and 3). We take this as consistent and convincing evidence of declines in the Cambodian populations of vultures.

Apparent increases in vulture numbers in both survey methods during the first half of the period (2003 to around 2010) may be due to increases in the proportion of the population recorded due to increases in the frequency of restaurants undertaken year on year until 2009 (Table SI). Vultures may become habituated to supplemental feeding sites (Zuberogoitia et al. 2010), causing increases in the number of individuals observed even without population growth. But the frequency of restaurants has remained relatively stable since 2010 (Table SI) suggesting that changes in the population, in the absence of other sources of systematic variation in detection rate, may reflect the general trend in species populations. In evaluating these trends it is also important to note that other studies have reported inter-species differences in feeding behaviour at vulture restaurants (Moreno-Opo et al. 2015) and so it is possible that the species have differing levels of dependence on supplemental feeding sources.

The sites in the eastern plains (LWS, SWS, PPWS and Sesan) have experienced much more rapid declines than CWS and PSPKLWS in the northern plains (Table 3, Figure 3). The more stable population of Slender-billed Vulture in relation to the other species (Figure 2) is likely to be because the majority of the remaining Slender-billed Vulture population is in PSPKLWS (73\% of the total population at the last census count of 2016) and the relative stability of the vulture population at this site compared with other locations (Figure 3). These changes in site population data are supported by the more anecdotal data on nests found and may represent the early warning signs of range decline which precedes local extirpation (Steadman 1995). In particular the recent decline in use of the Sesan site (Table 3, Figure 3), which appeared stable in the earlier study of Clements et al. (2013) may be a continuation of the decline in use across the eastern plains first identified by Clements et al. (2013). The maintenance of healthy vulture populations at multiple sites across the country is crucial for the 
long-term resilience of Cambodia's fragile vulture population, so that it can absorb shocks such as localised poisoning events. Modelling of long-term datasets suggest that supplemental feeding stations can be an important conservation tool to increase vulture survival rates (Oro et al. 2008) and the continued implementation of multiple vulture restaurants at different sites is recommended.

\section{The nature of the poisoning threat}

The rapid declines identified in this paper are most likely to be the result of poisoning incidents causing multiple mortality events (Table 5). The pharmacy survey and necropsy examinations of poisoned vultures have found that potentially harmful NSAIDs appear not to be available for veterinary use and were not responsible for recent suspected vulture poisoning incidents. Indeed, animal husbandry interviews showed that treatment of livestock with veterinary medicines is not a widespread practice in Cambodia. Nonetheless, a pre-emptive national ban on use of diclofenac and other harmful NSAIDs should be sought.

Carbofuran, one of the most toxic carbamate pesticides, caused vulture mortality in the only vulture poisoning incident in Cambodia for which toxicology testing has been undertaken. The absence of laboratory facilities in Cambodia has precluded previous testing. Recent efforts to test samples have only been made possible through collaboration with the Agri-food and Veterinary Authority (AVA) of Singapore. This international collaboration has also confirmed carbofuran to be used in a recent spike in wildlife poisoning cases associated with indiscriminate hunting practices around forest pools in Preah Vihear and Stung Treng provinces (WCS 2016). It is possible that carbamate pesticides were the undiagnosed chemicals responsible for historical vulture poisoning cases. However to date only six samples of separate wildlife poisoning incidents (including one Slender-billed Vulture) have received toxicology testing. All samples tested positive for carbofuran (WCS 2016). The low sample size means that conclusions are tentative, but suggest that carbamate pesticides pose a serious risk to vulture populations in Cambodia. Ongoing testing to determine the cause of vulture mortality is required to strengthen this case.

Reports of the hazardous impacts of pesticides on people and wildlife in Cambodia that specifically reference carbofuran date back to 2002 (EJF 2002). In this respect Cambodia may represent a different conservation paradigm to South Asia, where vulture poisoning is primarily caused by diclofenac and other NSAIDs (Green et al. 2004). Instead the poisoning threat to Cambodia's vultures appears more similar to vulture populations in Africa (Ogada 2014, Ogada et al. 2015), and Europe (Margalida et al. 2008; Hernández and Margalida 2009), where mortality due to exposure to carbamate pesticides is also recognised as a major source of mortality.

In order to conserve Cambodia's remaining vulture population a priority action must be to reduce, and if possible eliminate, indiscriminate hunting behaviour using baits and poisoning of forest pools using carbofuran and other pesticides. Visits to markets in Stung Treng and Preah Vihear provinces indicated that carbofuran is widely available where vulture population density in Cambodia is highest. In 2013, Cambodia acceded to the Rotterdam Convention, an international treaty that sets out to ban the use of carbofuran (European Union 2007, Rotterdam Convention 2013) and to provide general guidance on the use and trade regulations for toxic chemicals. However to the authors' knowledge, the available national legislation on chemicals (Ministry of Agriculture Forestry and Fisheries, 2012a and 2012b) do not include carbofuran in the list of banned pesticides. A high priority must be to review the list of banned pesticides to align with international recommendations. This legislative approach should be complemented by targeted awareness campaigns aiming to increase understanding of the risks to public health, domestic livestock and wildlife of the indiscriminate use of carbamate pesticides entering the food chain in order to change hunting behaviour practices.

\section{Conclusions}

Cambodia is a key site for the conservation of three 'Critically Endangered' Asian vulture species because it is a diclofenac-free population and is the last major stronghold in South-East Asia 
(BirdLife International 2017a, 2017b, 2017c). However despite more than 10 years of conservation efforts, populations appear to be falling, and new threats have been identified. The apparent rapid rise in reports of carbamate pesticide poisoning of wildlife in indiscriminate hunting practices is alarming and represents a serious conservation challenge. However, there are many positives too: diclofenac and NSAIDs are not a problem as far as we know, and birds continue to breed and fledge successfully. There is therefore potential for Cambodia to become an ark for vulture conservation in Asia.

Monitoring of Cambodia's vultures suggests that populations of all three species are undergoing a severe decline driven by secondary poisoning. In the absence of data to the contrary, this should be taken seriously, and the precautionary principle exercised. Priority recovery actions include: a) prevention of poisoning through national bans on harmful carbamate pesticides and diclofenac, coupled with education and awareness raising to reduce demand and use of such chemicals (an example of a recent demand focused awareness video is available https://www.youtube. $\mathrm{com} /$ watch? $\mathrm{v}=1 \mathrm{MpPmx}-\mathrm{GcH} 4 \&$ feature=youtu.be); b) training of personnel in priority protected areas in detection and response to poisoning incidents; $\mathrm{c}$ ) maintenance of a safe and reliable food source through vulture restaurants to ensure short-term survival of the remaining small vulture populations, and d) protection and restoration of large areas of deciduous dipterocarp forests and their ungulate fauna to enable long-term species recovery. A continued, national conservation programme, coordinated among multiple sites, is required to support the persistence of Cambodia's vulture population as the last stronghold of South-East Asian vultures.

\section{Supplementary Material}

To view supplementary material for this article, please visit https://oi.org/10.1017/ S0959270918000126

\section{Acknowledgements}

The Cambodia Vulture Conservation Project is a collaboration between the General Department of Administration for Nature Conservation and Protection (GDANCP) of the Ministry of Environment (MoE), the Forestry Administration (FA) of the Ministry of Agriculture, Forestry and Fisheries (MAFF), BirdLife International Cambodia Programme, the Wildlife Conservation Society (WCS), World Wide Fund for Nature (WWF), the Angkor Centre for Conservation of Biodiversity (ACCB). We would like to thank the Critical Ecosystem Partnership Fund for providing financial support to the Cambodia Vulture Conservation Project. The Critical Ecosystem Partnership Fund is a joint initiative of l'Agence Française de Développement, Conservation International, the European Union, the Global Environment Facility, the Government of Japan, the John D. and Catherine T. MacArthur Foundation, and the World Bank.

\section{References}

BirdLife International (2017a) Species factsheet: Gyps tenuirostris. Downloaded from http:// www.birdlife.org on 07/08/2017.

BirdLife International (2017b) Sarcogyps calvus (amended version of 2016 assessment). The IUCN Red List of Threatened Species 2017: Downloaded from http://www.birdlife.org on 07/08/2017.

BirdLife International (2017c) Gyps bengalensis. The IUCN Red List of Threatened Species 2017: Downloaded from http://www. birdlife.org on $07 / 08 / 2017$.
Bolker, B. (2016) bbmle: Tools for general maximum likelihood estimation. Available at: https://CRAN.R-project.org/package=bbmle

Clements, T., Gilbert, M., Rainey, H. J., Cuthbert, R. Eames, J. C., Pech, B. Seng, T., Tan, S. (2013) Vultures in Cambodia: population, threats and conservation. Bird Conserv. Internatn. 23: 7-24.

Das, D., Cuthbert, R. J., Jakati, R. D. and Prakash, V. (2011) Diclofenac is toxic to the Himalayan Vulture Gyps himalayensis. Bird Conserv. Internatn. 21: 72-75. 
EJF (2002) Death in small doses: Cambodia's pesticides problems and solutions. London, UK: Environmental Justice Foundation. Available: http://ejfoundation.org/report/death-smalldoses

European Union (2007) Decision 2007/416/ EC. Official Journal of European Union Commission L 156 of 16.06.2007, pp 30-31. http://eur-lex.europa.eu/LexUriServ/site/en/ oj/2007/1_156/1_15620070616eno0300031.pdf

Gilbert, M.,Watson, R.T., Virani, M.Z., Oaks, J.L., Ahmed, S., Chaudhry, M. J. I., Arshad, M., Mahmood, S., Ali, A. and Khan, A. A. (2006) Rapid population declines and mortality clusters in three Oriental white-backed vulture Gyps bengalensis colonies in Pakistan due to diclofenac poisoning. Oryx 40: 388-399.

Green, R. E., Newton, I., Shultz, S., Cunningham, A. A., Gilbert, M., Pain, D. J. and Prakash, V. (2004) Diclofenac poisoning as a cause of vulture population declines across the Indian subcontinent. J. Appl. Ecol. 41: 793-800.

Green, R. E., Taggart, M. A., Das, D., Pain, D. J., Sashi Kumar, C., Cunningham, A. A. and Cuthbert, R., (2006) Collapse of Asian vulture populations: risk of mortality from residues of the veterinary drug diclofenac in carcasses of treated cattle. J. Appl. Ecol. 43: 949-956.

Heng, T. C. (2015) Observed and projected changes in temperature and rainfall in Cambodia. Weather and Climate Extremes 7: 61-71.

Hernández, M. and Margalida, A. (2009) Poison-related mortality effects in the endangered Egyptian vulture (Neophron percnopterus) population in Spain. Eur. J. Wildl. Res. 55: 415-423.

Hiraldo, F., Delibes, M. and Calderón, J. (1979) El quebrantahuesos Gypaetus barbatus (L.). Madrid, Spain: ICONA. (Monografías 22).

Margalida, A., Heredia, R., Razin, M. and Hernández, M. (2008) Sources of variation in mortality of the Bearded Vulture Gypaetus barbatus in Europe. Bird Conserv. Internatn. 18: 1-10.

Margalida, A., Bogliani, G., Bowden, C. G., Donázar, J. A., Genero, F., Gilbert, M., Karesh, W. B., Kock, R., Lubroth, J., Manteca, X. and Naidoo, V. (2014) One Health approach to use of veterinary pharmaceuticals. Science 346(6215): 1296-1298.
Margalida, A. and Oliva-Vidal, P. (2017). The shadow of diclofenac hangs over European vultures. Nature Ecol. Evol. 1: 1050.

Mayfield, H. F. (1975) Suggestions for calculating nest success. Wilson Bull. 87: 456-466.

Ministry of Agriculture, Forestry and Fisheries (2012a) Promulgation of Law on management of Pesticide and Agricultural Fertilizer. Royal Kram. No. NS/RKM/0112/005. [Khmer language] 14/OI/2012. Royal Government of Cambodia Regulation, Phnom Penh, Cambodia. Available: http:// bnglaw.net/download_temp.php?lawid= 5007 \&lawlang $=$ KH\&action $=1 \& \mathrm{nid}=$ $1 \&$ page=directory.php English translation available: http://cambodiantr.gov.kh/ kcfinder/upload/files/Law \% 20on \% 20 Management \% 20of\% 20Pesticides \% 20 and $\%$ 2oFertilizers \% 20-\% 2oEN.pdf

Ministry of Agriculture, Forestry and Fisheries (2012b) Prakas No. 484 on List of Pesticide (including list of banned pesticide) [Khmer language], 26/11/2012. Royal Government of Cambodia Regulation, Phnom Penh, Cambodia.

Moleon, M., Sanchez-Zapata, J. A., Margalida, A., Carrete, M., Owen-Smith, N. and Donazar, J.A. (2014) Humans and scavengers: the evolution of interactions and ecosystem services. BioScience 64: 394-403.

Moreno-Opo, R., Trujillo, A., Arredondo, A., González, L. M. and Margalida, A. (2015) Manipulating size, amount and appearance of food inputs to optimize supplementary feeding programs for European vultures. Biol. Conserv. 181: 27-35.

Oaks, J. L., Gilbert, M., Virani, M. Z., Watson, R. T., Meteyer, C. U., Rideout, B. A., Shivaprasad, H. L., Ahmed, S., Chaudhry, M. J. I., Arshad, M., Mahmood, S., Ali, A. and Khan, A. A. (2004) Diclofenac residues as the cause of vulture population decline in Pakistan. Nature 427: 630-633.

Ogada, D. L. (2014) The power of poison: pesticide poisoning of Africa's wildlife. Ann. NY Acad. Sci. 1322: 1-20.

Ogada, D. L., Keesing, F. and Virani, M. Z. (2012a) Dropping dead: causes and consequences of vulture population declines worldwide. Ann. N Y Acad. Sci. 1249: 57-71.

Ogada, D. L., Torchin, M. E., Kinnaird, M. F. and Ezenwa, V. O. (2012b) Effects of vulture 
declines on facultative scavengers and potential implications for mammalian disease transmission. Conserv. Biol. 26: 453-46o.

Ogada, D. L., Shaw, P., Beyers, R. L., Buij, R., Murn, C., Thiollay, J. M., Beale, C. M., Holdo, R. M., Pomeroy, D., Baker, N. and Krüger, S. C. (2015) Another continental vulture crisis: Africa's vultures collapsing toward extinction. Conserv. Lett. 9: 89-97.

Oro, D., Margalida, A., Carrete, M., Heredia, R. and Donázar, J. A., (2008) Testing the goodness of supplementary feeding to enhance population viability in an endangered vulture. PLoS One 3: e4084

Pain, D. J., Bowden, C. G. R., Cunningham, A. A., Cuthbert, R., Das, D., Gilbert, M., Jakati, R. D., Jhala, Y., Khan, A. A., Naidoo, V., Oaks, J. L., Parry-Jones, J., Prakash, V., Rahmani, A., Ranade, S. P., Baral, H. S., Senacha, K. R., Saravanan, S., Shah, N., Swan, G., Swarup, D., Taggart, M. A., Watson, R. T., Virani, M.Z., Wolter, K. and Green, R. E. (2008) The race to prevent the extinction of South Asian vultures. Bird Conserv. Internatn. 18: $\mathrm{S}_{3} \mathrm{O}-\mathrm{S}_{4} 8$.

$\mathrm{R}$ Core Team (2016) R: A language and environment for statistical computing. Vienna, Austria: R Foundation for Statistical
Computing. Available at: http://www.Rproject.org/.

Rotterdam Convention (2013) Cambodia 01/03/2013. Available: http://www.pic.int/ Countries/CountryProfile/tabid/1087/ language/en-US/Default.aspx

Steadman, D. (1995) Prehistoric extinctions of Pacific island birds: biodiversity meets zooarchaeology. Science 267: 1123-1131.

Sudarshan, M.K., Madhusudana, S.N., Mahendra, B. J., Rao, N. S. N., Ashwath Narayana, D. H., Abdul Rahman, S., Meslin, F-X., Lobo, D. and Ravikumar, K. (2007) Assessing the burden of human rabies in India: results of a national multi-center epidemiological survey. Internatn. J. Infectious Dis. 11: 29-35.

WCS (2016) Carbofuran poisoning at the interface between wildlife, livestock, and humans. WCS Cambodia internal report. Available at: http://cambodia.wcs.org/Admin-Plus/ Docustore.aspx ? Com mand=Core Download\&EntryId $=32128$

Zuberogoitia, I., Martínez, J. E., Margalida, A., Gómez, I., Azkona, A. and Martínez, J. A. (2010) Reduced food availability induces behavioural changes in griffon vulture. Ornis Fennica 87: 52-60.

ROBIN LOVERIDGE ${ }^{1,2 *}$, JONATHAN C. EAMES ${ }^{1}$, PHEARUN SUM ${ }^{1}$

${ }^{1}$ BirdLife International Cambodia Programme, \# 32A, St 494, Phsar Deurm Tkov,

Chamkarmon, Phnom Penh, Cambodia.

${ }^{2}$ Environment Department, University of York, Heslington, YO1o 5 NG, York, UK.

SIMON P. MAHOOD, ALISTAIR MOULD, STEFAN HARRISON, TOM CLEMENTS, MATHIEU PRUVOT

WCS Cambodia, \# 21, Street 21 Sangkat Tonle Bassac, Phnom Penh, Cambodia.

GERARD EDWARD RYAN4,5, RACHEL CROUTHERS4, SOK KO 4

4WWF Cambodia, \# 21 street 322, St 29, Phnom Penh, Cambodia.

5 School of BioSciences, University of Melbourne, 3010, Victoria, Australia.

OLIVER GRAY-READ

Angkor Center for Conservation of Biodiversity, Kbal Spean, Phnom Kulen National Park, Banteay Srei District, Siem Reap Province, Cambodia.

* Author for correspondence; e-mail: robin.loveridge@gmail.com

Received 5 September 2016; revision accepted 26 April 2018; Published online 25 September 2018 